\title{
Estresse térmico no acúmulo de prolina livre de plântulas de guandu oriundas de sementes tratadas com poliaminas
}

\section{Temperature stress in accumulation of free proline of pigeonpea seedlings from seeds treated with polyamines}

\author{
Jéssica da Silva ${ }^{1 *}$; Vanessa Aparecida Villanova Saccini²; \\ Durvalina Maria Mathias dos Santos ${ }^{3}$
}

\begin{abstract}
Resumo
Estudou-se os efeitos do tratamento de sementes de guandu com poliaminas no conteúdo de prolina de plântulas com o intuito de verificar se a aplicação destas poliaminas atenua o estresse térmico na germinação e no crescimento inicial de plântulas e, constatar se a putrescina e espermidina exógenas induzem ao acúmulo de prolina, podendo este aminoácido ser indicativo bioquímico-fisiológico em plântulas que estejam sob temperaturas subótimas e supraótimas. As sementes de guandu, cv. BRS Mandarim e cv. Caqui, tratadas com solução de $0,5 \mathrm{mM}$ de putrescina ou espermidina, foram submetidas a temperaturas subótimas $\left(20^{\circ} \mathrm{C}, 18^{\circ} \mathrm{C}, 16^{\circ} \mathrm{C}\right.$ e $\left.14^{\circ} \mathrm{C}\right)$ e supraótimas $\left(36^{\circ} \mathrm{C}, 38^{\circ} \mathrm{C}, 40^{\circ} \mathrm{C}\right.$ e $\left.44^{\circ} \mathrm{C}\right)$ por 24 horas e 48 horas. Após estes períodos, foram submetidas à $25^{\circ} \mathrm{C}$ até o $10^{\circ}$ dia, quando foram verificados a porcentagem de germinação das sementes, o conteúdo de prolina das partes vegetativas e a massa de matéria seca das plântulas. Foi utilizado o delineamento inteiramente casualizado em esquema fatorial $3 \times 4 \times 2+3$ (soluções com poliaminas, estresse térmico por resfriamento/aquecimento, tempos de exposição aos estresses, mais os fatores adicionais em $25^{\circ} \mathrm{C}$ com $0,0 \mathrm{mM}$ e $0,5 \mathrm{mM}$ de Put e Spd), com quatro repetições de 25 sementes. Os resultados foram submetidos à análise de variância e as médias comparadas pelo teste de Tukey a 5\% de probabilidade, separadamente para cada cultivar. Ambas as poliaminas exógenas atenuam os efeitos do resfriamento e aquecimento, contribuindo para o incremento de sementes germinadas. Também, a putrescina e espermidina exógenas atenuaram os efeitos das temperaturas adversas por induzir o acúmulo de prolina, o qual conduz ao ajuste osmótico, embora esta resposta fisiológica não tenha minimizado os efeitos negativos do estresse térmico no crescimento de plântulas de guandu. A prolina pode ser considerada indicador bioquímico-fisiológico em plântulas de ambas as cultivares de guandu tratadas com as poliaminas sob temperaturas estressantes.

Palavras-chave: Cajanus cajan (L.) Millsp., espermidina, forrageira, osmólito, putrescina, temperaturas
\end{abstract}

\begin{abstract}
It was studied the effects of seed treatment with polyamines of pigeonpea for proline content of seedling in order to verify that the application of these polyamines attenuates temperature stress on germination and early seedling growth, and see if exogenous putrescine and spermidine induce the accumulation of proline, this amino acid may be biochemical and physiological indicator in seedlings that are under suboptimal temperatures and supraoptmail. The seeds of pigeonpea cv. BRS Mandarin and cv. Caqui, treated with a solution of $0.5 \mathrm{mM}$ of putrescine and spermidine, were subjected to

${ }^{1}$ Bióloga, M.e em Produção Vegetal, Centro Universitário Luterano de Ji-Paraná, CEULJI/ULBRA, Ji-Paraná, RO. E-mail: jeh_

2 Eng $^{a}$ Agra ${ }^{a}$, M.e em Produção Vegetal, Universidade Estadual Paulista, UNESP/FCAV, Jaboticabal, SP. E-mail: van_saccini@

${ }^{3}$ Bióloga, $\operatorname{Prof}^{a} \operatorname{Dr}^{\mathrm{a}}$, Dept ${ }^{\circ}$ de Biologia Aplicada à Agropecuária, UNESP/FCAV, Jaboticabal, SP. E-mail: dumaria@fcav.unesp.br Autor para correspondência
\end{abstract} silva@hotmail.com hotmail.com 
suboptimal temperature $\left(20^{\circ} \mathrm{C}, 18^{\circ} \mathrm{C}, 16^{\circ} \mathrm{C}\right.$ and $\left.14^{\circ} \mathrm{C}\right)$ and supraoptimal $\left(36^{\circ} \mathrm{C}, 38^{\circ} \mathrm{C}, 40^{\circ} \mathrm{C}\right.$ and $\left.44^{\circ} \mathrm{C}\right)$ for 24 hours and 48 hours. After these periods, were subjected to $25^{\circ} \mathrm{C}$ until day 10, when the percentage of seed germination were observed, the proline content of vegetative parts and the dry mass of the seedlings. A completely randomized design in a factorial arrangement was used $3 \times 4 \times 2+3$ (solutions with polyamines, temperature stress by cooling/heating, time of exposure to stress, plus additional factors em $25^{\circ} \mathrm{C}$ with $0.0 \mathrm{mM}$ and $0.5 \mathrm{mM}$ of Put and Spd), with four replicates of 25 seeds. The results were submitted to analysis of variance and means were compared by Tukey test at $5 \%$ probability, separately for each cultivar. Both exogenous polyamines attenuate the effects of cooling and heating, contributing to the growth of germinated seeds. Also, putrescine and spermidine exogenous mitigated the adverse effects by inducing proline accumulation, which leads to osmotic adjustment temperatures, although this physiological response has not minimized the negative effects of temperature stress on seedling growth of pigeonpea. Proline can be considered biochemical and physiological indicator in seedlings of both cultivars of pigeonpea treated with polyamines under temperature stress.

Key words: Cajanus cajan (L.) Millsp, spermidine, forage, osmolyte, putrescine, temperature

\section{Introdução}

Os vegetais, por serem organismos sésseis, estão expostos aos estresses abióticos como a seca, salinidade, metais pesados, deficiência ou toxidez nutricional, bem como altas e baixas temperaturas. A sobrevivência e a distribuição das plantas no planeta são determinadas, entre outros fatores, pela temperatura. $\mathrm{O}$ estresse causado pelas temperaturas subótimas e supraótimas altera a homeostase celular, provoca severo atraso no crescimento e desenvolvimento vegetal e, em muitos casos, conduz à senescência programada (THAKUR et al., 2010; SZABADOS et al., 2011).

Em resposta aos vários estresses, as plantas se protegem disparando alterações bioquímicofisiológicas, dentre as quais se destaca o ajuste osmótico, mecanismo que promove o acúmulo de moléculas orgânicas de baixo peso molecular, conhecidas como solutos ou osmólitos compatíveis, os quais não interferem nas reações metabólicas do vegetal (ASHRAF et al., 2011; SZABADOS et al., 2011). Entre os compostos orgânicos acumulados em plantas sob estresses, encontra-se a prolina, aminoácido essencial, que em plantas sob estresse pode ter função osmoprotetora, auxiliando na manutenção da integridade celular de proteínas, enzimas e membranas (ASHRAF et al., 2011). Embora muitos estudos relacionem o acúmulo de prolina à indução do ajuste osmótico para proteção aos efeitos dos estresses como às altas e baixas temperaturas (SZABADOS; SAVOURÉ, 2010; CAO et al., 2011; CVIKROVÁ et al., 2012), a correlação entre o acúmulo de prolina e a tolerância das plantas aos estresses, para vários autores, ainda não está totalmente compreendida (ABDUL JALEEL et al., 2007; BRITO et al., 2008; SZABADOS; SAVOURÉ, 2010; ASHRAF et al., 2011).

Em plantas superiores, encontram-se moléculas sinalizadoras de vários processos fisiológicos e, sobretudo, dos estresses impostos ao vegetal (ASHRAF et al., 2011; WIMALASEKERA; TEBARTZ; SCHERER, 2011). As poliaminas têm sido identificadas como uma classe essencial de reguladores vegetais endógenos, representada pela putrescina, espermidina, espermina e cadaverina. Constituem-se compostos nitrogenados alifáticos, policatiônicos, de baixo peso molecular, encontrados em todos os organismos vivos (GILL; TUTEJA, 2010). Nas últimas décadas tem aumentado muito o interesse dos pesquisadores sobre as poliaminas, devido ao relevante efeito na fisiologia da planta e, sobretudo, nas respostas aos estresses abióticos (GILL; TUTEJA, 2010; WIMALASEKERA; TEBARTZ; SCHERER, 2011). A utilização exógena de poliaminas está sendo considerada boa alternativa para aumentar a resistência das plantas aos vários estresses (HUSSAIN et al., 2011).

Mediante as condições ambientais adversas impostas às plantas, existe a necessidade da busca 
de vegetais que apresentem amplitude de adaptação aos estresses. O guandu (Cajanus cajan (L.) Millsp.), leguminosa forrageira é considerado, no período da entressafra, alternativa para a provisão de alimento de alta qualidade para os animais e armazenamento de forragem (NENE; HALL; SHEILA, 1990). Possui capacidade de crescer em períodos adversos que são limitantes ao crescimento de outras espécies vegetais, e por ser resistente aos vários estresses ambientais, é considerada planta de múltiplo uso (NENE; HALL; SHEILA, 1990; SAXENA, 2008).

Neste trabalho estudou-se os efeitos do estresse térmico no acúmulo de prolina e crescimento inicial de plântulas de guandu oriundas de sementes tratadas com as poliaminas putrescina e espermidina. Este estudo teve o intuito de verificar se a aplicação destas poliaminas em sementes atenua o estresse térmico na germinação e no crescimento inicial de guandu. Também, constatar se a putrescina e espermidina exógenas induzem ao acúmulo de prolina, podendo este aminoácido ser indicativo bioquímico-fisiológico em plântulas que estejam sob temperaturas subótimas e supraótimas.

\section{Material e Métodos}

Os experimentos foram instalados no laboratório de Fisiologia Vegetal da Faculdade de Ciências Agrárias e Veterinárias, FCAV, da Universidade Estadual Paulista, UNESP, Câmpus de Jaboticabal, nos anos de 2011 e 2012.

Foram utilizadas caixas de germinação, tipo Gerbox, previamente esterilizadas e revestidas com uma folha de papel de germinação umedecido com $15 \mathrm{~mL}$ de solução contendo $0,0 \mathrm{mM} ; 0,5 \mathrm{mM}$ de putrescina (Put) ou 0,5mM de espermidina ( $\mathrm{Spd}$ ).

Para a imposição do estresse térmico, foram utilizadas temperaturas dentro da faixa $12,8^{\circ} \mathrm{C}$ a $43^{\circ} \mathrm{C}$ indicadas por Nene, Hall e Sheila (1990) para o desenvolvimento da cultura de guandu em campo. O estresse térmico por resfriamento constou das temperaturas subótimas de $20^{\circ} \mathrm{C}$, $18^{\circ} \mathrm{C}, 16^{\circ} \mathrm{C}$ e $14^{\circ} \mathrm{C}$, enquanto o aquecimento apresentou as temperaturas supraótimas de $36^{\circ} \mathrm{C}$, $38^{\circ} \mathrm{C}, 40^{\circ} \mathrm{C}$ e $44^{\circ} \mathrm{C}$. Para o tratamento controle foi considerada a temperatura de $25^{\circ} \mathrm{C}$. As sementes foram submetidas ao estresse térmico por 24 ou 48 horas, de acordo com a metodologia de Lopes et al. (2010) e, posteriormente, foram transferidas ao germinador a $25^{\circ} \mathrm{C}$ com fotoperíodo de 12 horas, onde permaneceram até o $10^{\circ}$ de semeadura.

Para a montagem dos experimentos de cada cultivar, foi utilizado o delineamento inteiramente casualizado em esquema fatorial $3 \times 4 \times 2+3$ (soluções com poliaminas, estresse térmico por resfriamento/ aquecimento, tempos de exposição aos estresses, mais os fatores adicionais em $25^{\circ} \mathrm{C}$ com $0,0 \mathrm{mM}$ e $0,5 \mathrm{mM}$ de Put e $\mathrm{Spd}$ ). Foram realizadas quatro repetições de 25 sementes.

Para analisar os teores de prolina livre e o crescimento das plântulas foram utilizadas as temperaturas subótimas de $18^{\circ} \mathrm{C}$ e $14^{\circ} \mathrm{C}$ e as supraótimas de $36^{\circ} \mathrm{C} \mathrm{e} 40^{\circ} \mathrm{C}$, pois testes preliminares indicaram respostas significativas para os teores de prolina e para o crescimento.

O delineamento experimental utilizado foi $o$ inteiramente casualizado em esquema fatorial $3 \times 2 \times 2+3$ (soluções com poliaminas, estresse térmico por resfriamento/aquecimento, tempos de exposição aos estresses, mais os fatores adicionais em $25^{\circ} \mathrm{C}$ com $0,0 \mathrm{mM}$ e $0,5 \mathrm{mM}$ de Put eSpd).

Foi utilizada a metodologia de Bates, Waldren e Teare (1973), na qual a partir de 0,5g de massa fresca das partes vegetativas obtiveram-se as reações com ácido sulfosalicílico, ácido acético glacial, ácido ninhidrina e tolueno. As leituras da absorbância foram em $520 \mathrm{~nm}$. Os teores de prolina foram calculados em mmoles de prolina/g massa fresca $\left(\mu \mathrm{mol} \mathrm{g} \mathrm{g}^{-1} \mathrm{MF}\right)$.

O crescimento das plântulas foi verificado mediante obtenção da massa seca da parte aérea e da raiz primária, em estufa de circulação forçada de ar em temperatura de $80^{\circ} \mathrm{C}$ por 72 horas e pesagem em balança analítica Denver Instrument Company AA-200. 
A análise estatística foi realizada separadamente para cada cultivar. Os dados foram submetidos à análise de variância pelo teste $\mathrm{F}$ e as médias comparadas pelo teste de Tukey a 5\% de probabilidade. Os dados de germinação de sementes foram transformados em arco seno $\sqrt{ } \mathrm{x} / 100$ e os desdobramentos dos graus de liberdade foram submetidos à análise de regressão polinomial.

\section{Resultados}

As temperaturas estressantes, tanto subótimas quanto supraótimas, causaram redução significativa da germinação de sementes de ambas as cultivares de guandu (Tabelas e Figuras 1 e 2). A diminuição da temperatura reduziu acentuadamente a germinação em 24 horas, tanto para a cv. BRS Mandarim quanto para cv. Caqui (Figura 1A e 1B, respectivamente). Esta resposta também ocorreu nas temperaturas supraótimas, sendo esta condição confirmada, na cv. Caqui, pela morte do embrião na temperatura de $44^{\circ} \mathrm{C}$ (Tabelas 1 e 2).

Figura 1. Germinação de sementes (\%) de guandu, no $10^{\circ}$ dia após a semeadura, sob diferentes temperaturas de resfriamento e períodos de exposição aos estresses. (A) cv. BRS Mandarim; (B) cv. Caqui. *Médias seguidas da mesma letra maiúscula (entre tempos de exposição ou temperaturas) e minúscula (dentro de cada tempo de exposição ou temperatura) não diferem entre si pelo teste de Tukey $(\mathrm{P}>0,05)$.
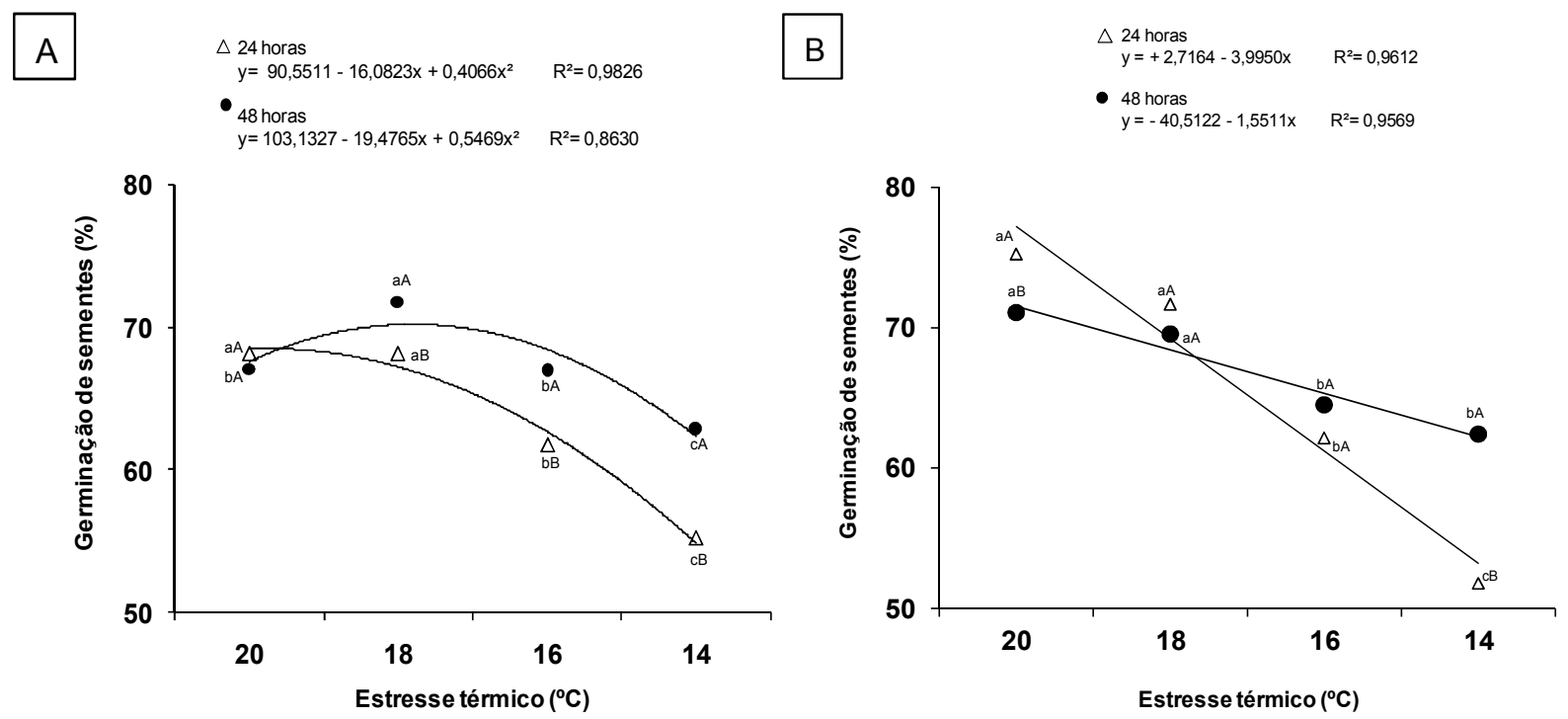

Fonte: Elaboração dos autores.

A exposição das sementes de guandu às temperaturas subótimas em 24 e 48 horas mostra a sensibilidade do guandu, uma espécie tropical, às condições de frio, as quais ocasionaram acentuada redução da germinação das sementes no menor período de exposição (Tabelas 1 e 2; Figuras 1A e 1B). Por outro lado, quando submetidas a temperaturas supraótimas, as sementes mostraramse sensibilizadas pela temperatura após a exposição prolongada (Tabelas 1 e 2, Figuras 2Ae 2C).
As poliaminas exógenas incrementaram a germinação das sementes da cv. BRS Mandarim sob as temperaturas supraótimas, enquanto que na cv. Caqui, somente a Spd aumentou a germinação das sementes (Tabela 1 e 2; Figura 2B). Ainda, nesta cultivar a Put exógena provocou menor germinação das sementes (Tabela 2). 
Tabela 1. Análise de variância das temperaturas subótimas, tempos de exposição e poliaminas exógenas na germinação de sementes (\%) de guandu, cv. BRS Mandarim e cv. Caqui, no 10 dia após a semeadura. Jaboticabal, SP. 2011- 2012.

\begin{tabular}{|c|c|c|}
\hline Temperaturas (TR) & cv. BRS Mandarim & cv. Caqui \\
\hline & Germinação (\%) & Germinação (\%) ${ }^{1}$ \\
\hline $20^{\circ} \mathrm{C}$ & $67,63 \mathrm{a}$ & $73,91 \mathrm{a}$ \\
\hline $18^{\circ} \mathrm{C}$ & $69,99 \mathrm{a}$ & $70,61 \mathrm{a}$ \\
\hline $16^{\circ} \mathrm{C}$ & $64,32 \mathrm{~b}$ & $63,32 \mathrm{~b}$ \\
\hline $14^{\circ} \mathrm{C}$ & $59,05 \mathrm{c}$ & $57,91 \mathrm{c}$ \\
\hline Teste F & $43,01 * *$ & $77,77 * *$ \\
\hline Tempos de exposição (TE) & Germinação (\%) ${ }^{1}$ & Germinação (\%) ${ }^{1}$ \\
\hline 24 horas & $63,31 \mathrm{~b}$ & $65,22 \mathrm{~b}$ \\
\hline 48 horas & $67,18 \mathrm{a}$ & $66,88 \mathrm{a}$ \\
\hline Teste F & $28,64 * *$ & $4,07 *$ \\
\hline Poliaminas (P) & Germinação $(\%)^{1}$ & Germinação (\%) ${ }^{1}$ \\
\hline $0,0 \mathrm{mM}$ & $65,12 \mathrm{a}$ & $64,79 \mathrm{a}$ \\
\hline $0,5 \mathrm{mM} \mathrm{Put}^{2}$ & 65,09 a & $66,20 \mathrm{a}$ \\
\hline $0,5 \mathrm{mM} \mathrm{Spd}^{3}$ & $65,53 \mathrm{a}$ & $67,15 \mathrm{a}$ \\
\hline Teste $\mathrm{F}$ & $0,15^{\text {ns }}$ & $2,78^{\mathrm{ns}}$ \\
\hline Interações & Germinação $(\%)^{1}$ & Germinação (\%) ${ }^{1}$ \\
\hline TRxTE & $6,38 * *$ & $15,83 * *$ \\
\hline $\mathrm{TRxP}$ & $0,18^{\mathrm{ns}}$ & $1,89^{\text {ns }}$ \\
\hline TExP & $0,42^{\text {ns }}$ & $0,34^{\mathrm{ns}}$ \\
\hline TRxTExP & $0,55^{\text {ns }}$ & $1,57^{\mathrm{ns}}$ \\
\hline Tratamentos Adicionais & Germinação (\%) $)^{1}$ & Germinação (\%) ${ }^{1}$ \\
\hline $25^{\circ} \mathrm{C}+0,0 \mathrm{mM}$ & 74,19 a & $74,19 \mathrm{a}$ \\
\hline $25^{\circ} \mathrm{C}+0,5 \mathrm{mMPut}$ & 69,01 a & $69,01 \mathrm{a}$ \\
\hline $25^{\circ} \mathrm{C}+0,5 \mathrm{mMSpd}$ & $70,45 \mathrm{a}$ & $70,45 \mathrm{a}$ \\
\hline Teste $\mathrm{F}$ & $4,49 *$ & $1,75^{\text {ns }}$ \\
\hline Média Fatorial & 65,25 & 66,05 \\
\hline Média Trat. Adicionais & 75,54 & 71,22 \\
\hline Adicional vs. Fatorial & $90,11 * *$ & $17,43^{* *}$ \\
\hline C.V. $(\%)$ & 5,33 & 6,07 \\
\hline
\end{tabular}

${ }^{1}$ Dados de \% de germinação transformados em arco seno raiz quadrada de x/100; ${ }^{2}$ Putrescina; ${ }^{3}$ Espermidina; ns : não significativo $(\mathrm{P}>0,05) ;{ }^{*}$ : significativo $(\mathrm{P}<0,05) ; * *$ : significativo $(\mathrm{P}<0,01) ;$ C.V.: coeficiente de variação.

Fonte: Elaboração dos autores.

O conteúdo de prolina e o crescimento inicial das plântulas de ambas as cultivares de guandu apresentaram resposta significativa frente às condições de temperatura, tempos de exposição e poliaminas exógenas a que as sementes foram expostas (Tabela 3).

Observou-se que, na cv. BRS Mandarim, os tempos de exposição às temperaturas subótimas causaram aumento nos teores de prolina das plântulas de guandu. Ainda, verificou-se que a temperatura de $14^{\circ} \mathrm{C}$ incrementou os teores de prolina no menor período de exposição (24 horas), indicando que em menor temperatura necessita-se de menos tempo para ocorrer o incremento de prolina. Verificando os resultados de $18^{\circ} \mathrm{C}$, nota-se que, o maior acúmulo de prolina ocorreu em 48 horas (Figura 3A e 3B). 
Tabela 2. Análise de variância das temperaturas supraótimas, tempos de exposição e poliaminas exógenas na germinação de sementes (\%) de guandu, cv. BRS Mandarim e cv. Caqui, no $10^{\circ}$ dia após a semeadura. Jaboticabal, SP. 2011- 2012.

\begin{tabular}{|c|c|c|}
\hline \multirow{2}{*}{ Temperaturas (TR) } & cv. BRS Mandarim & cv. Caqui \\
\hline & Germinação (\%) & Germinação (\%) ${ }^{1}$ \\
\hline $36^{\circ} \mathrm{C}$ & $80,15 \mathrm{a}$ & $76,24 \mathrm{a}$ \\
\hline $38^{\circ} \mathrm{C}$ & $82,45 \mathrm{a}$ & $70,45 \mathrm{~b}$ \\
\hline $40^{\circ} \mathrm{C}$ & $74,34 \mathrm{~b}$ & $64,64 \mathrm{c}$ \\
\hline $44^{\circ} \mathrm{C}$ & $71,54 \mathrm{c}$ & $--^{2}$ \\
\hline Teste F & $50,25 * *$ & $45,80 * *$ \\
\hline Tempos de exposição (TE) & Germinação (\%) & Germinação (\%) ${ }^{1}$ \\
\hline 24 horas & $79,53 \mathrm{a}$ & 73,13 a \\
\hline 48 horas & $74,72 \mathrm{~b}$ & $67,76 \mathrm{~b}$ \\
\hline Teste $\mathrm{F}$ & $45,68^{* *}$ & $29,36 * *$ \\
\hline Poliaminas (P) & Germinação (\%) ${ }^{1}$ & Germinação (\%) ${ }^{1}$ \\
\hline $0,0 \mathrm{mM}$ & $75,46 \mathrm{~b}$ & $70,78 \mathrm{ab}$ \\
\hline $0,5 \mathrm{mM} \mathrm{Put}^{3}$ & 77,87 a & $68,63 \mathrm{~b}$ \\
\hline $0,5 \mathrm{mM} \mathrm{Spd}^{4}$ & $78,03 \mathrm{a}$ & $71,92 \mathrm{a}$ \\
\hline Teste F & $5,44 * *$ & $3,81 *$ \\
\hline Interações & Germinação (\%) & Germinação (\%) ${ }^{1}$ \\
\hline TRxTE & $5,04 * *$ & $1,75^{\mathrm{ns}}$ \\
\hline TRxP & $3,71 * *$ & $0,87^{\mathrm{ns}}$ \\
\hline TExP & $2,78^{\text {ns }}$ & $0,15^{\text {ns }}$ \\
\hline TRXTExP & $7,18 * *$ & $2,55^{*}$ \\
\hline Tratamentos Adicionais & Germinação (\%) ${ }^{1}$ & Germinação (\%) ${ }^{1}$ \\
\hline $25^{\circ} \mathrm{C}+0,0 \mathrm{mM}$ & $72,05 \mathrm{~b}$ & $74,19 \mathrm{a}$ \\
\hline $25^{\circ} \mathrm{C}+0,5 \mathrm{mMPut}$ & $75,07 \mathrm{ab}$ & 69,01 a \\
\hline $25^{\circ} \mathrm{C}+0,5 \mathrm{mMSpd}$ & $79,51 \mathrm{a}$ & $70,44 \mathrm{a}$ \\
\hline Teste F & $4,63 *$ & $1,62^{\mathrm{ns}}$ \\
\hline Média Fatorial & 77,12 & 70,44 \\
\hline Média Trat. Adicionais & 75,54 & 71,21 \\
\hline Adicional vs. Fatorial & $2,20^{\mathrm{ns}}$ & $0,35^{\mathrm{ns}}$ \\
\hline C.V. (\%) & 4,53 & 5,95 \\
\hline
\end{tabular}

${ }^{1}$ Dados de \% de germinação transformados em arco seno raiz quadrada de $\mathrm{x} / 100$;

${ }^{2}$ Ausência de germinação, morte das sementes (este dado não foi considerado na análise de variância); ${ }^{3}$ Putrescina; ${ }^{4}$ Espermidina; ns : não significativo $(\mathrm{P}>0,05)$; : significativo $(\mathrm{P}<0,05)$; ** : significativo $(\mathrm{P}<0,01)$; C.V.: coeficiente de variação.

Fonte: Elaboração dos autores.

A Put exógena, sob temperaturas subótimas mais severas, provocou aumento significativo dos teores de prolina na parte aérea, embora nas raízes primárias tenha reduzido o conteúdo deste aminoácido (Figura 3C e 3D).

Com 24 horas de exposição às temperaturas subótimas, a Put incrementou aumento dos teores de prolina da parte aérea das plântulas da cv. BRS Mandarim (Figura 3E), embora na raiz primária esta poliamina tenha reduzido o conteúdo deste osmólito (Figura 3F). Ambas as poliaminas exógenas causaram redução do conteúdo de prolina da parte aérea sob resfriamento por maior tempo de exposição (Figura 3E), enquanto que nas raízes a Spd conduziu ao acúmulo de prolina (Figura 3F). 


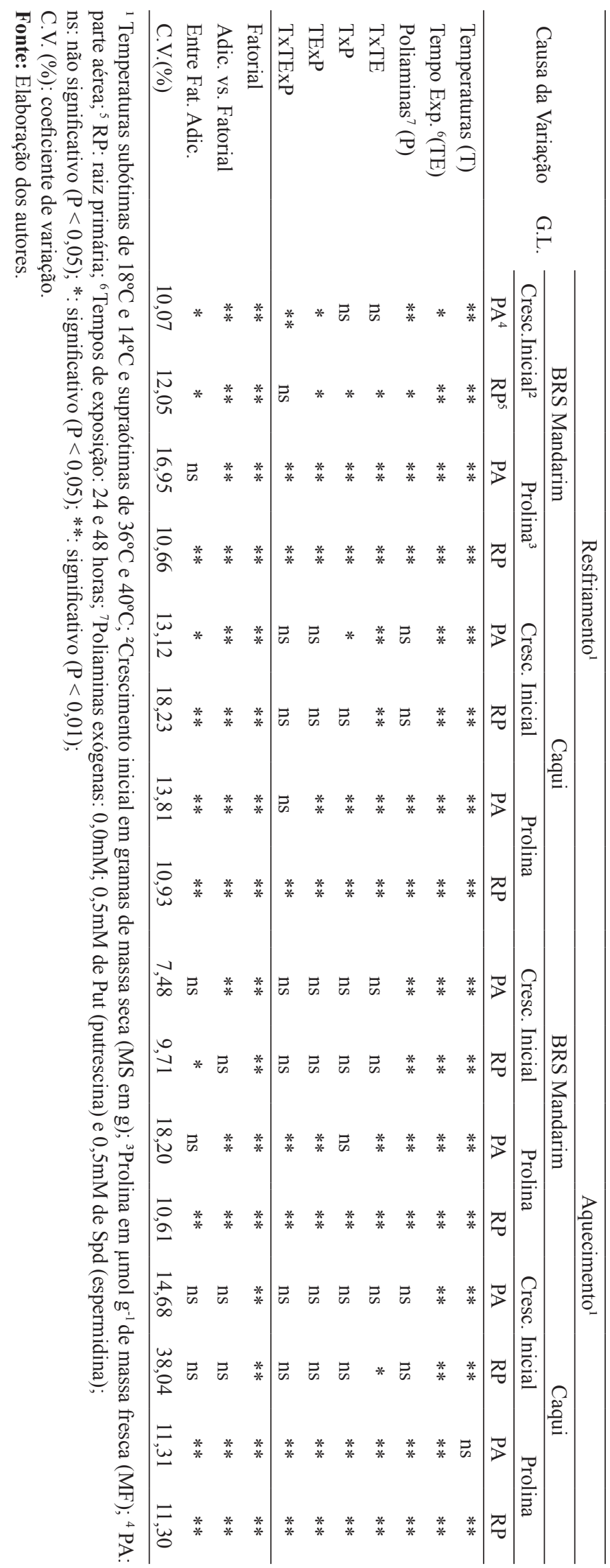

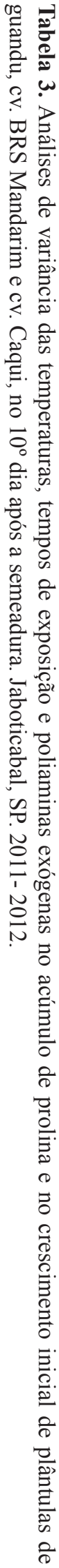


Figura 2. Germinação de sementes (\%) de guandu, cv. BRS Mandarim, em temperaturas supraótimas, sob efeito dos tempos de exposição (A) e poliaminas exógenas (B) e cv. Caqui, sob efeito das temperaturas de aquecimento, no $10^{\circ}$ dia após a semeadura. *Médias seguidas da mesma letra maiúscula (entre tempos de exposição ou temperaturas) e minúscula (dentro de cada tempo de exposição ou temperatura) não diferem entre si pelo teste de Tukey $(\mathrm{P}>0,05)$.
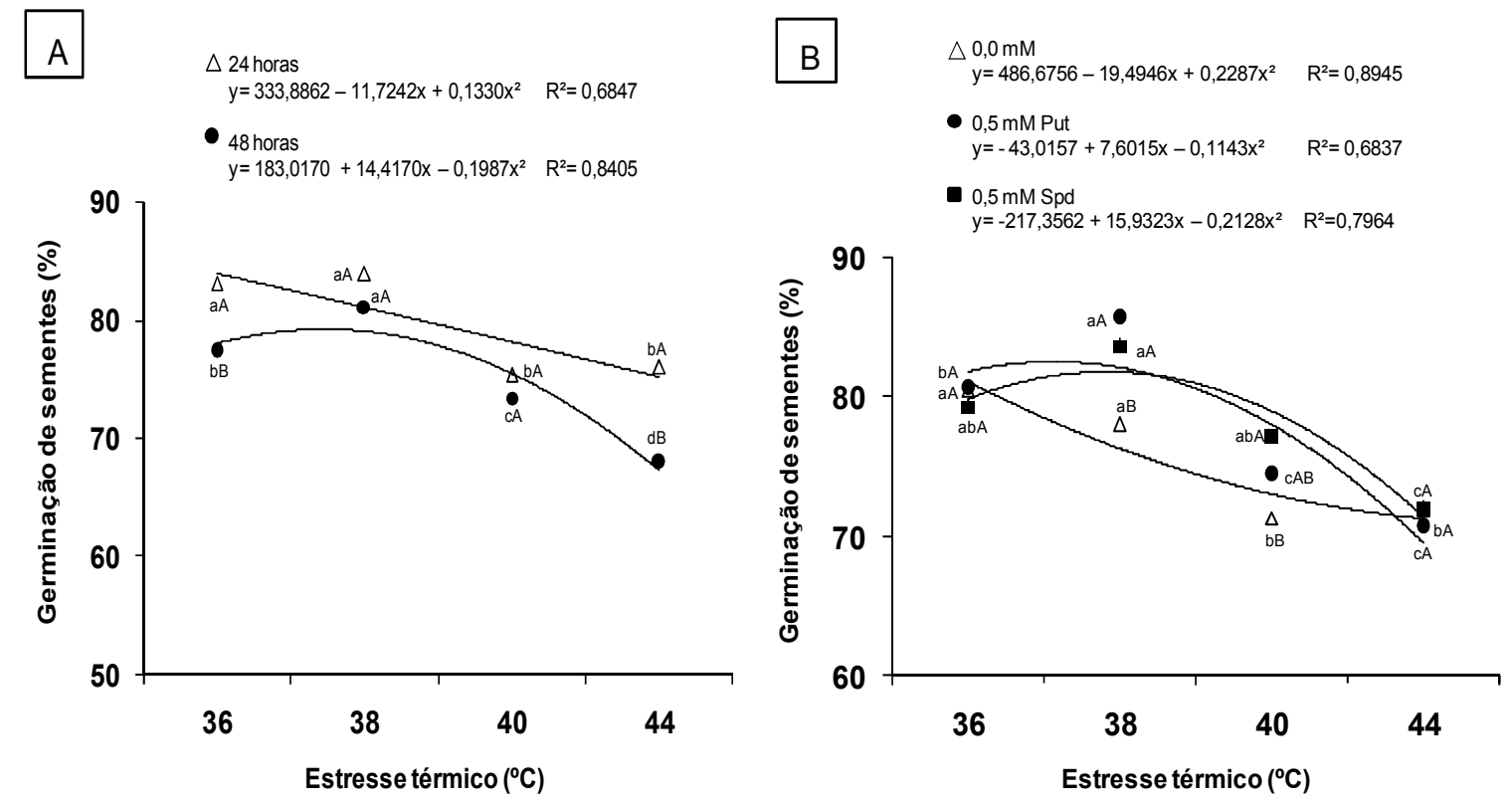

Fonte: Elaboração dos autores.

O estresse térmico por temperaturas subótimas causou efeito significativo no crescimento inicial das plântulas da cv. BRS Mandarim. Houve maior crescimento da raiz primária, tanto sob $18^{\circ} \mathrm{C}$ quanto sob $14^{\circ} \mathrm{C}$, por 48 horas de exposição (Figura 4A). A aplicação das poliaminas possibilitou ainda, no período de 24 horas de exposição às temperaturas subótimas, maior crescimento das plântulas (Figura 4C e 4D), embora a poliamina Put tenha causado maior crescimento em $18^{\circ} \mathrm{C}$ (Figura 4B).

Os resultados da cv. Caqui referentes aos tempos de exposição às temperaturas subótimas revelaram que, no menor período ambas as temperaturas provocaram aumento nos teores de prolina das plântulas de guandu (Figura 5A e 5B). Sob resfriamento menos severo $\left(18^{\circ} \mathrm{C}\right)$, a $\mathrm{Spd}$ causou aumento dos teores de prolina, tanto na parte aérea quanto nas raízes primárias (Figura 5C e 5D). Ainda, em relação à Put, a Spd aumentou o conteúdo de prolina nas raízes primárias sob temperatura de $14^{\circ} \mathrm{C}$ (Figura 5D). Observa-se que, na parte aérea e nas raízes primárias da cv. Caqui, apenas a Spd possibilitou aumento acentuado dos teores de prolina na exposição de 24 e 48 horas às temperaturas subótimas (Figuras 5E e 5F).

$\mathrm{O}$ crescimento inicial das plântulas da cv. Caqui foi maior em $18^{\circ} \mathrm{C}$, independentemente do período de exposição (Figura 6A e 6B). Além disso, na temperatura subótima mais severa, o crescimento foi influenciado positivamente pela Put, a partir do incremento da massa seca da parte aérea, embora a $18^{\circ} \mathrm{C}$ tenha havido maior crescimento, independente das poliaminas exógenas (Figura 6C). 
Figura 3. Conteúdo de prolina de plântulas de guandu, cv. BRS Mandarim, em temperaturas subótimas, no $10^{\circ}$ dia após a semeadura. Parte aérea (A, C e E) e raiz primária (B, D e F). *Médias seguidas da mesma letra, maiúscula (entre tempos de exposição ou temperatura) e minúscula (dentro de cada tempo de exposição ou temperatura), não diferem entre si pelo teste de Tukey $(\mathrm{P}>0,05)$.

A
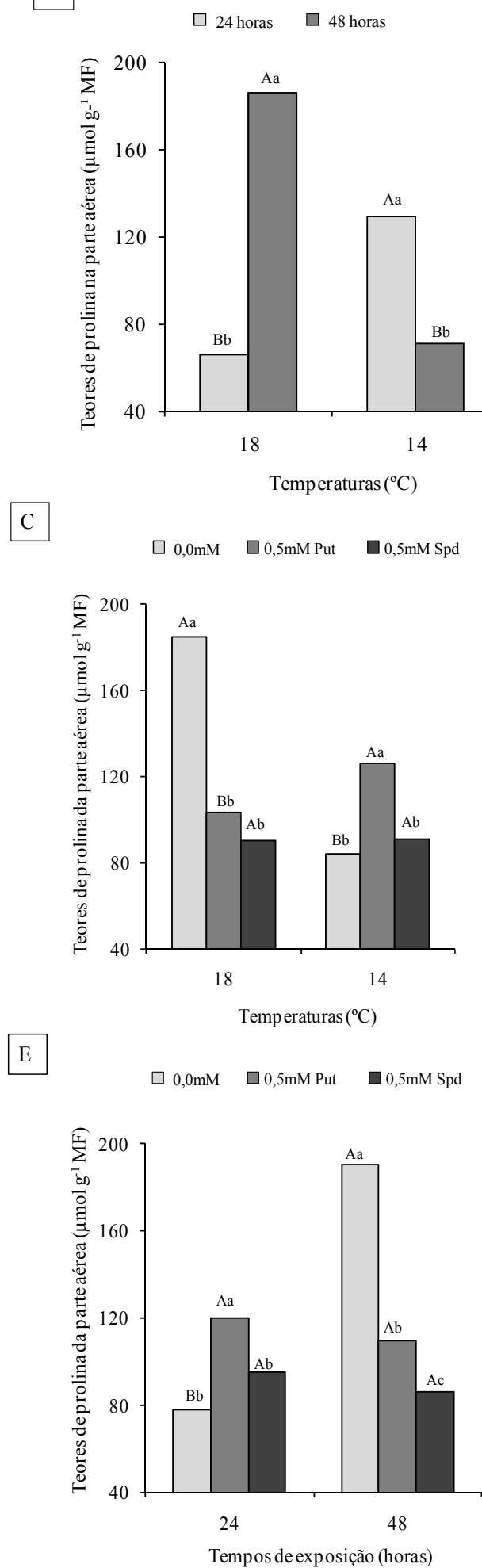

B

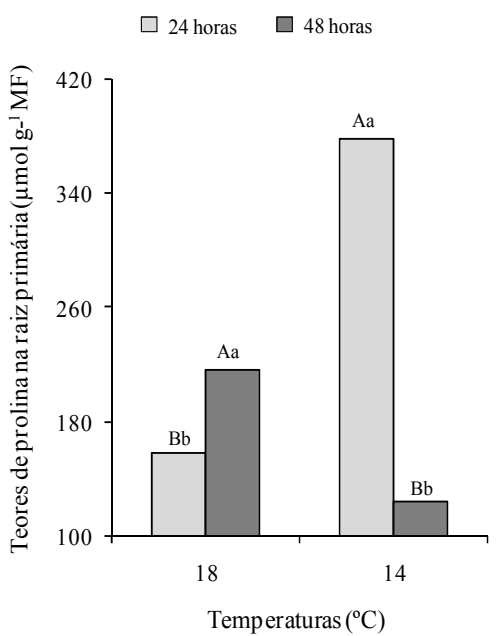

$\mathrm{D}$

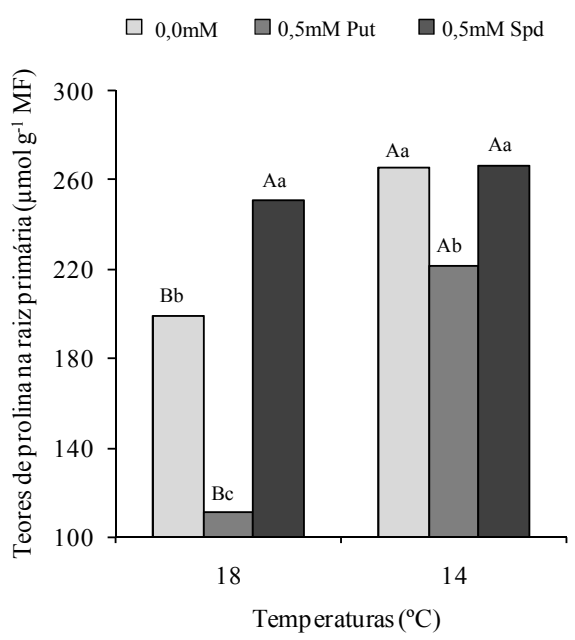

F

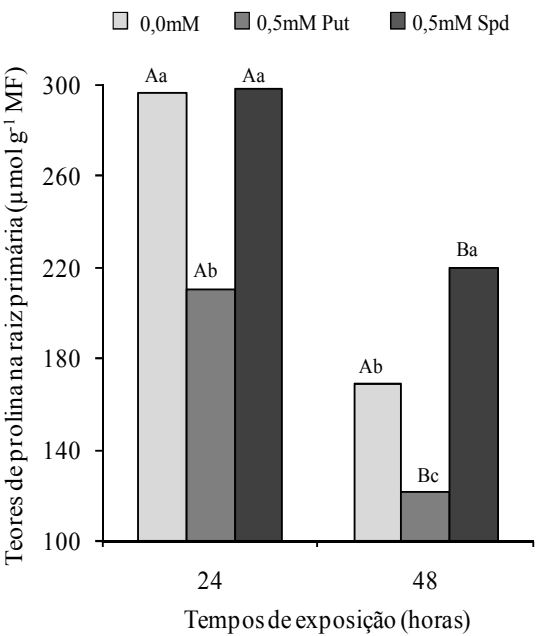

Fonte: Elaboração dos autores. 
Figura 4. Crescimento inicial de plântulas de guandu, cv. BRS Mandarim, em temperaturas subótimas, no $10^{\circ}$ dia após a semeadura. Parte aérea (D) e raiz primária (A, B e C). *Médias seguidas da mesma letra, maiúscula (entre tempos de exposição ou temperatura) e minúscula (dentro de cada tempo de exposição ou temperatura), não diferem entre si pelo teste de Tukey $(\mathrm{P}>0,05)$.

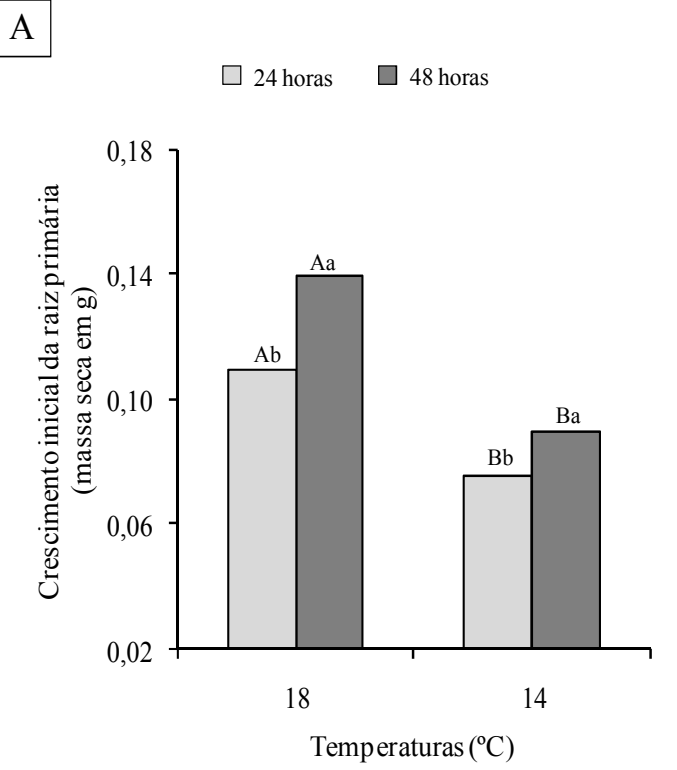

$\mathrm{C}$

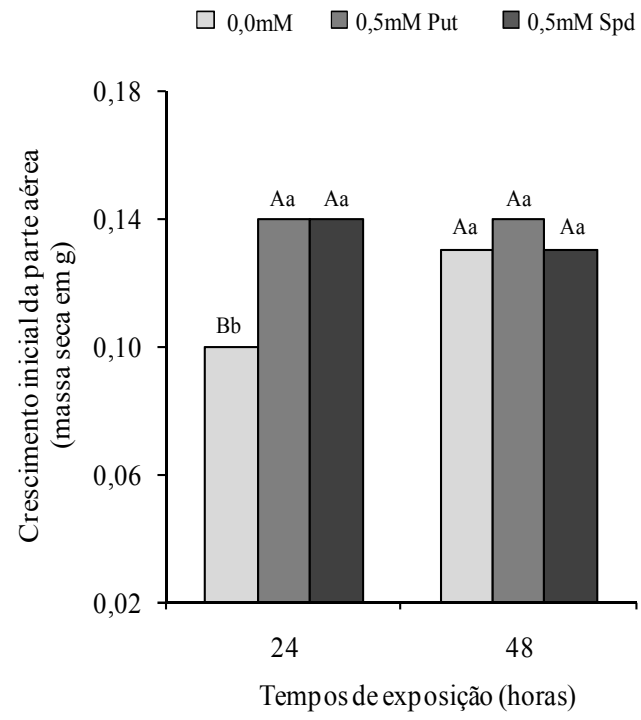

B

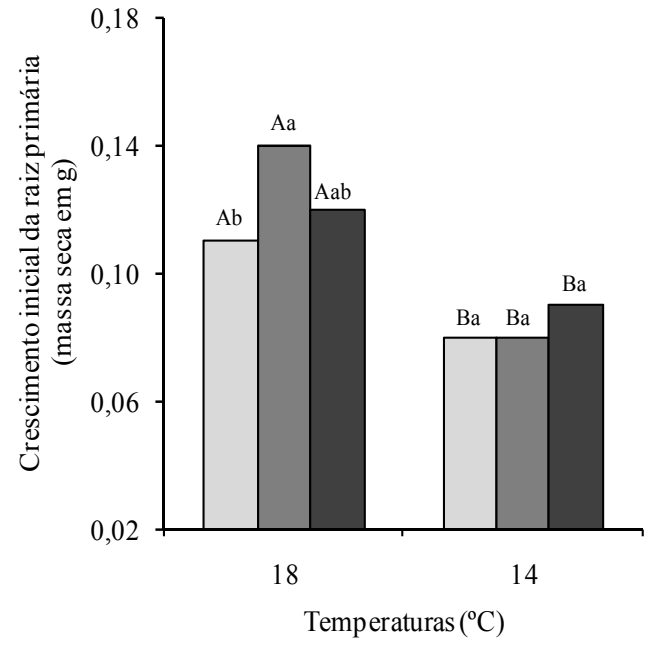

$\mathrm{D}$

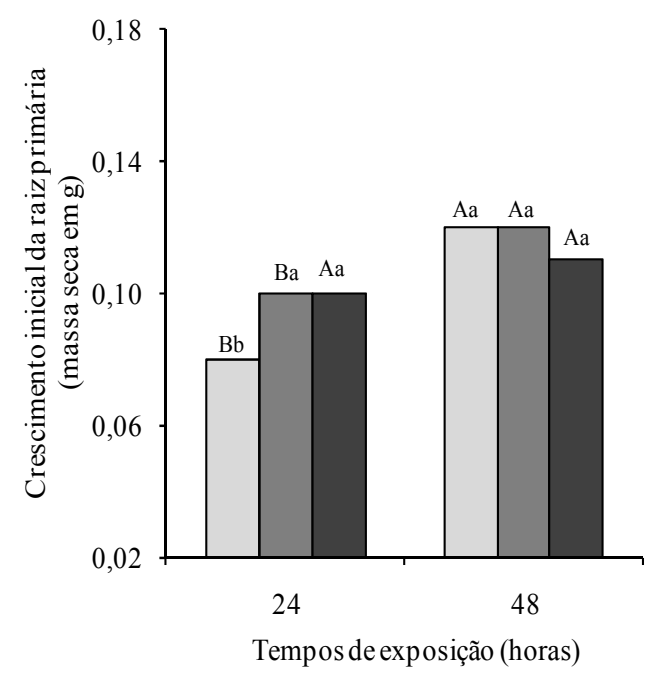

Fonte: Elaboração dos autores. 
Figura 5. Conteúdo de prolina de plântulas de guandu, cv. Caqui, em temperaturas subótimas, no $10^{\circ}$ dia após a semeadura. Parte aérea (A, C e E) e raiz primária (B, D e F). *Médias seguidas da mesma letra, maiúscula (entre tempos de exposição ou temperatura) e minúscula (dentro de cada tempo de exposição ou temperatura), não diferem entre si pelo teste de Tukey $(\mathrm{P}>0,05)$.

\section{A}

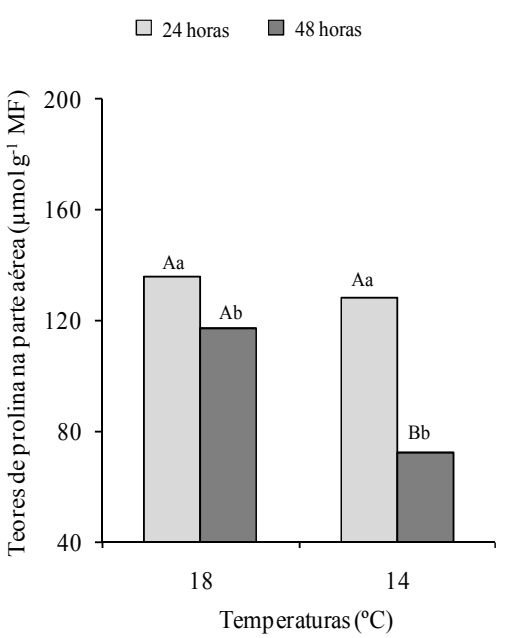

C

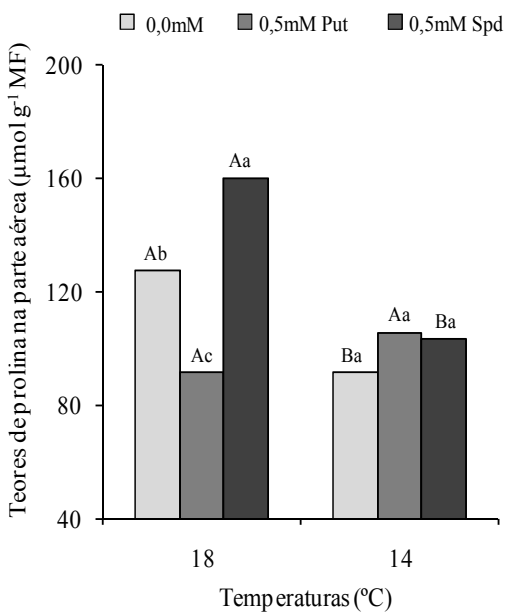

E
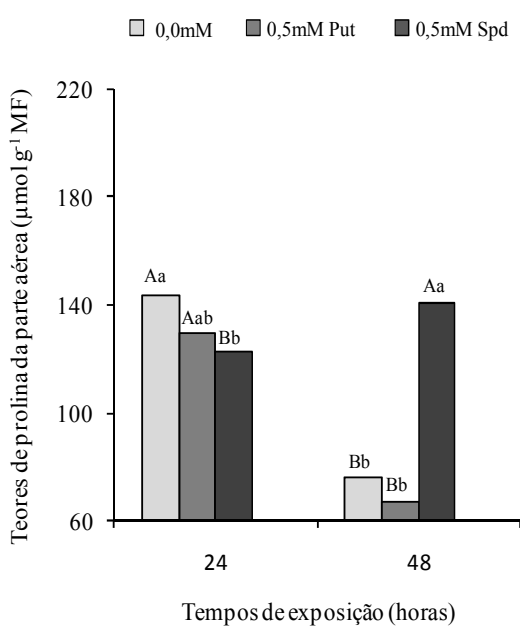

B

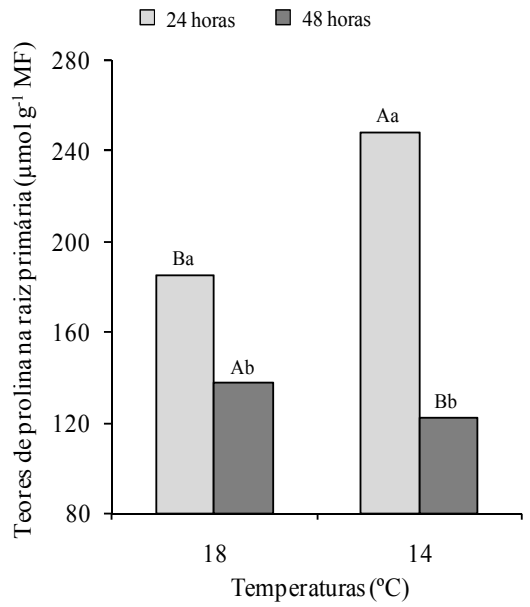

$\mathrm{D}$

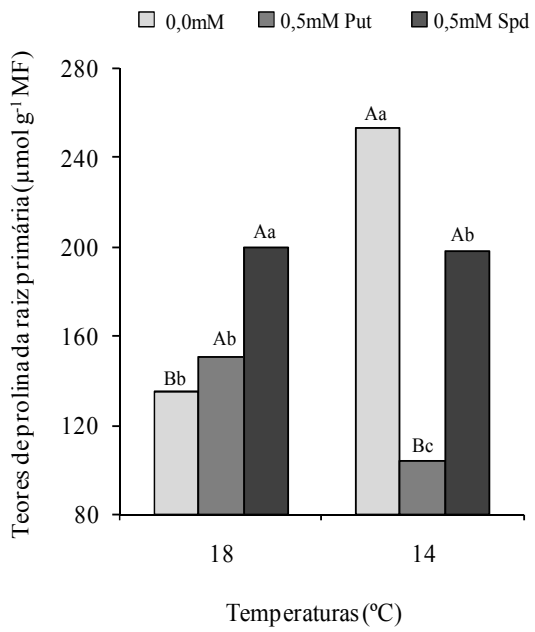

F

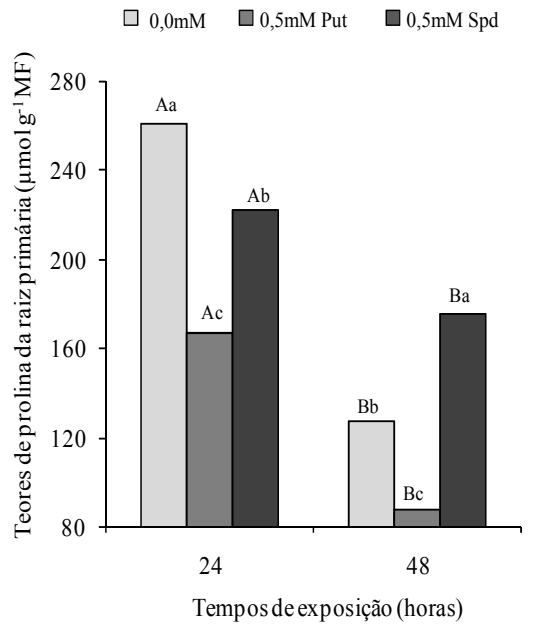

Fonte: Elaboração dos autores. 
Figura 6. Crescimento inicial de plântulas de guandu, cv. Caqui, em temperaturas subótimas, no $10^{\circ}$ dia após a semeadura. Parte aérea (A e C) e raiz primária (B). *Médias seguidas da mesma letra, maiúscula (entre tempos de exposição ou temperatura) e minúscula (dentro de cada tempo de exposição ou temperatura), não diferem entre si pelo teste de Tukey $(\mathrm{P}>0,05)$.

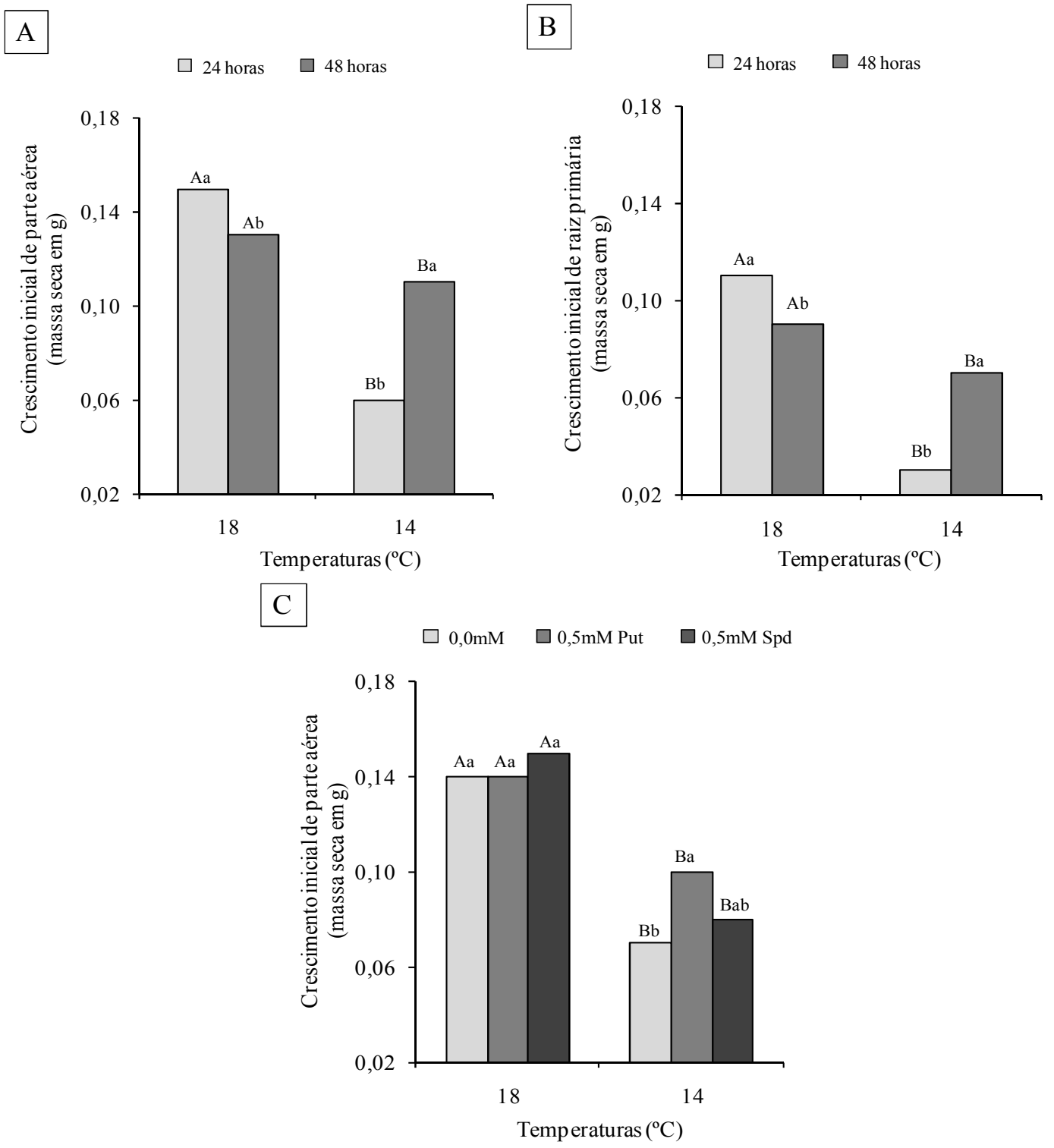

Fonte: Elaboração dos autores.

As temperaturas supraótimas causaram aumento dos teores de prolina nas plântulas da $\mathrm{cv}$. BRS Mandarim submetidas a $36^{\circ} \mathrm{C}$ por 24 horas e a $40^{\circ} \mathrm{C}$ por maior tempo (Figuras 7A e 7B). Os teores de prolina destas plântulas não foram incrementados pela aplicação das poliaminas, independente do tempo a que ficaram expostas às temperaturas supraótimas (Figura 7C e 7D), embora tenha havido significativa diferença no acúmulo deste osmólito nas raízes primárias entre os períodos de exposição (Figura 7D), bem como observado na temperatura de $36^{\circ} \mathrm{C}$ (Figura 7E). 
Figura 7. Conteúdo de prolina de plântulas de guandu, cv. BRS Mandarim, em temperaturas supraótimas, no $10^{\circ}$ dia após a semeadura. Parte aérea (A e C) e raiz primária (B, D e E). *Médias seguidas da mesma letra, maiúscula (entre tempos de exposição ou temperatura) e minúscula (dentro de cada tempo de exposição ou temperatura), não diferem entre si pelo teste de Tukey $(\mathrm{P}>0,05)$.

A

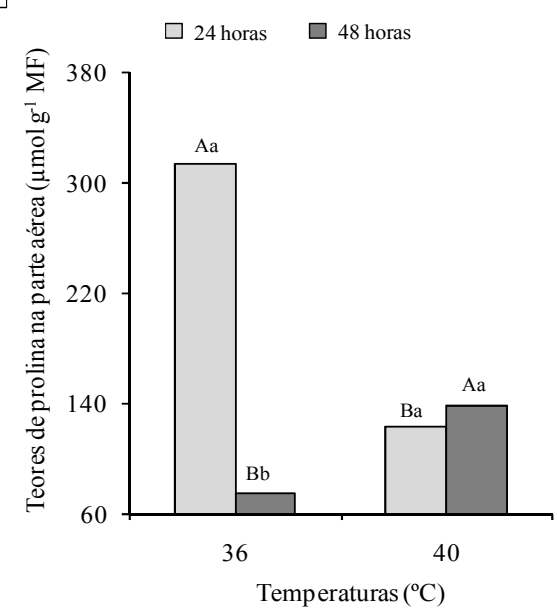

C

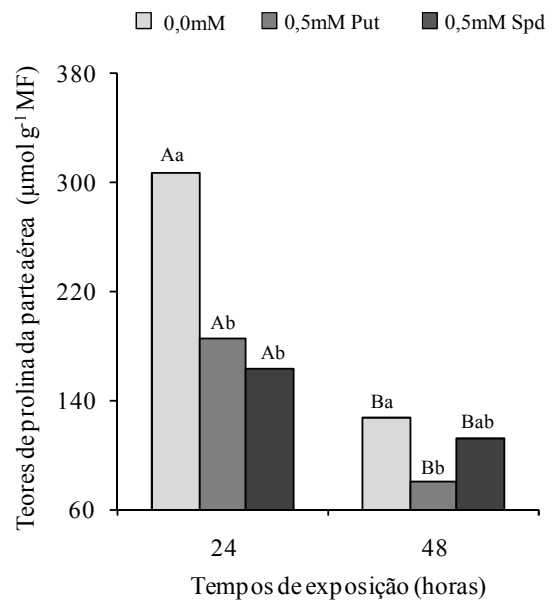

B

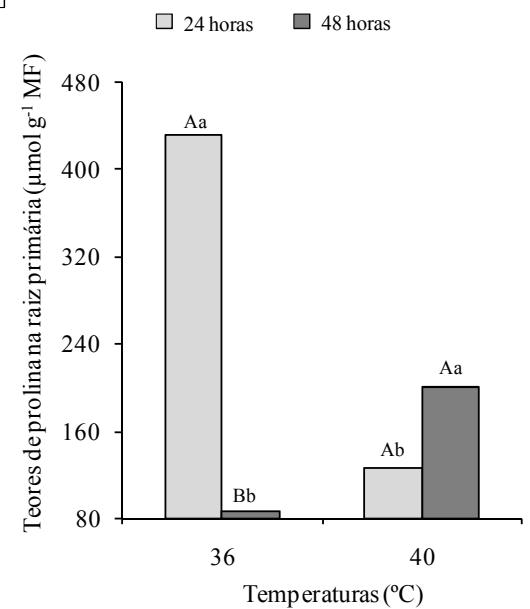

$\mathrm{D}$

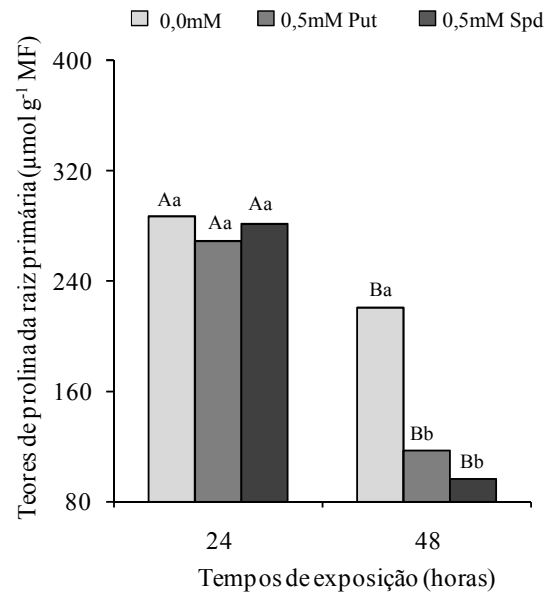

E

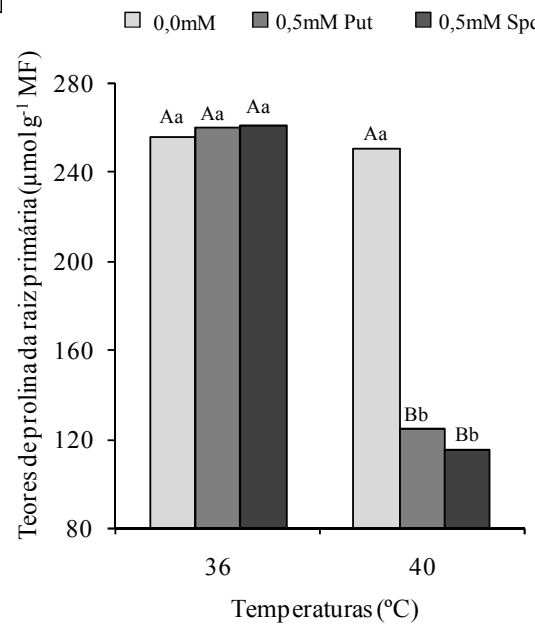

Fonte: Elaboração dos autores. 
Os resultados da cv. Caqui nos tempos de exposição às temperaturas supraótimas revelaram que, em 48 horas, ambas as temperaturas provocaram acentuado aumento nos teores de prolina da parte aérea das plântulas (Figura 8A), enquanto que nas raízes primárias, a maior exposição provocou aumento dos teores de prolinana temperatura de $40^{\circ} \mathrm{C}$ (Figura 8B). A aplicação da Spd possibilitou incremento dos teores de prolina nas raízes submetidas ao aquecimento por 24 horas (Figura $8 \mathrm{D}$ ) e à temperatura de $36^{\circ} \mathrm{C}$ (Figura $8 \mathrm{E}$ ), enquanto que com 48 horas de exposição, a Put reduziu os teores de prolina nestas plântulas (Figura 8C e 8D). O crescimento da raiz primária das plântulas foi decrescente conforme ocorreu aumento da temperatura e do tempo de exposição (Figura 9A).
$\mathrm{Na}$ ausência de estresse térmico, as poliaminas não causaram diferença significativa nos teores de prolina das partes aéreas das plântulas da cv. BRS Mandarim (Figura 10A). Nas raízes primárias, ambas as poliaminas diminuíram estes teores (Figura 10B). O crescimento inicial da parte aérea não respondeu significativamente à aplicação das poliaminas (Figura 10C), enquanto que aplicação de Spd possibilitou melhor crescimento nas raízes (Figura 10D).

$\mathrm{Na}$ cv. Caqui, ambas as poliaminas exógenas incrementaram os teores de prolina da parte aérea (Figura 11A). Nas raízes apenas o tratamento Spd promoveu aumento acentuada da prolina (Figura 11B). Os resultados do crescimento destas plântulas evidenciam a redução da massa seca em gramas, oriunda da aplicação da Put (Figuras 11C e 11D).

Figura 8. Conteúdo de prolina de plântulas de guandu, cv. Caqui, em temperaturas supraótimas, no $10^{\circ}$ dia após a semeadura. Parte aérea (A e C) e raiz primária (B, D e E). *Médias seguidas da mesma letra, maiúscula (entre tempos de exposição ou temperatura) e minúscula (dentro de cada tempo de exposição ou temperatura), não diferem entre si pelo teste de Tukey $(\mathrm{P}>0,05)$.
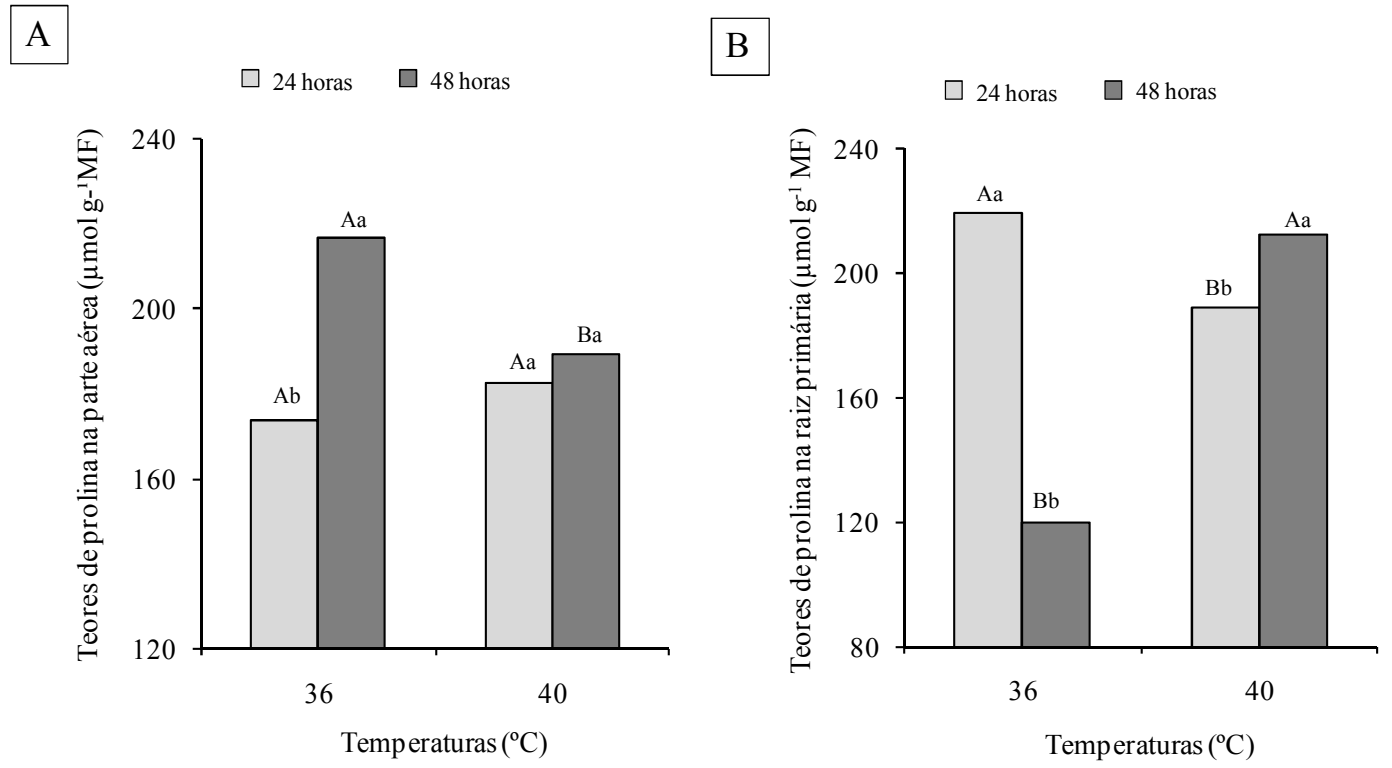
$\mathrm{C}$

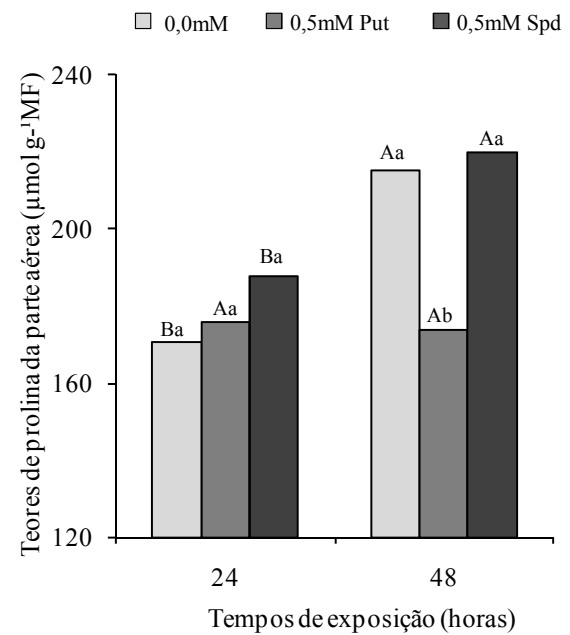

$\mathrm{D}$

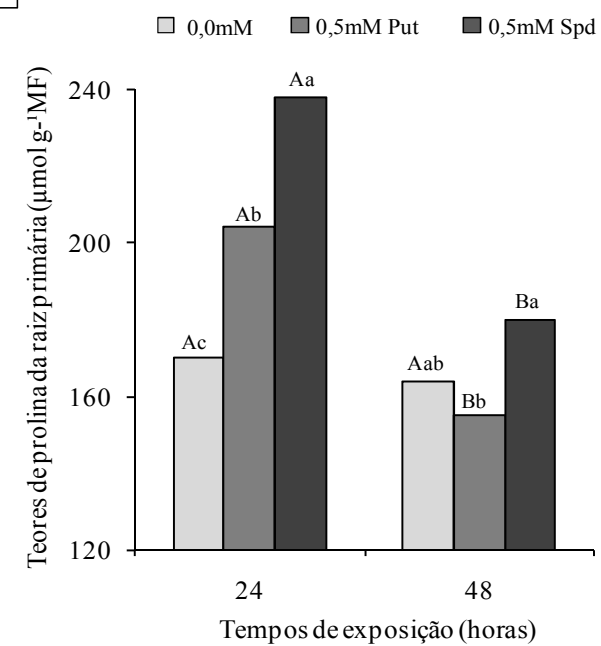

E

Fonte: Elaboração dos autores.

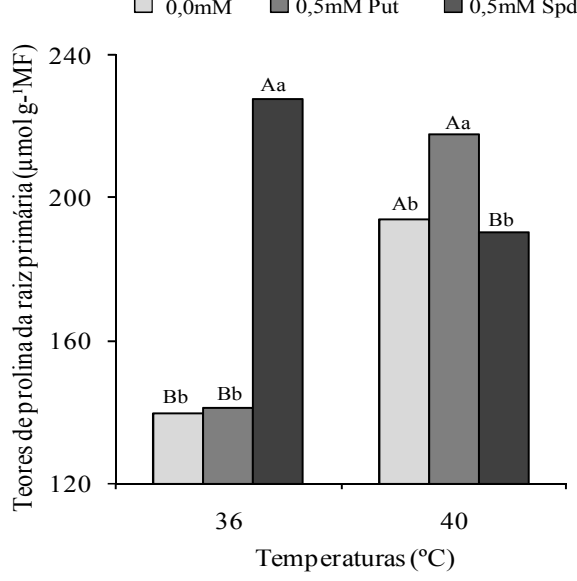

Figura 9. Crescimento inicial de plântulas de guandu, cv. Caqui, em temperaturas supraótimas, no $10^{\circ}$ dia após a semeadura. Raiz primária (A). *Médias seguidas da mesma letra, maiúscula (entre tempos de exposição ou temperatura) e minúscula (dentro de cada tempo de exposição ou temperatura), não diferem entre si pelo teste de Tukey $(\mathrm{P}>0,05)$.

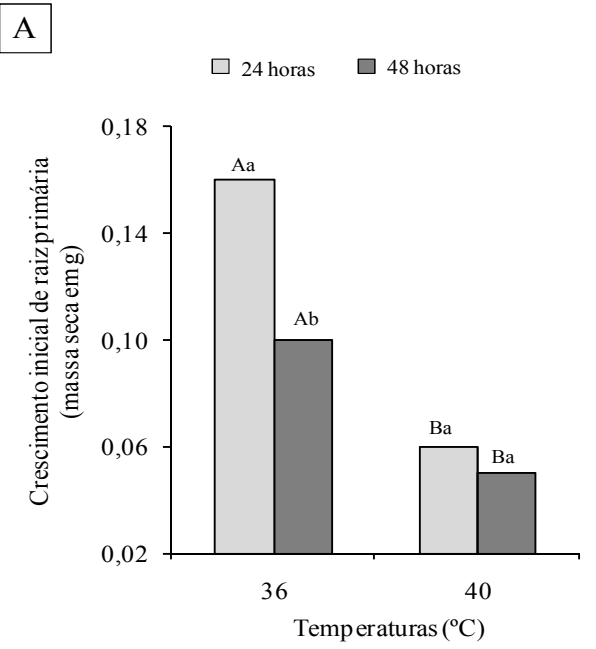

Fonte: Elaboração dos autores. 
Figura 10. Conteúdo de prolina e crescimento inicial de plântulas de guandu, cv. BRS Mandarim, em temperatura não estressante e poliaminas exógenas, no $10^{\circ}$ dia após a semeadura. Parte aérea (A e C) e raiz primária (B e D). *Médias seguidas da mesma letra, maiúscula (entre tempos de exposição ou temperatura) e minúscula (dentro de cada tempo de exposição ou temperatura), não diferem entre si pelo teste de Tukey $(\mathrm{P}>0,05)$.

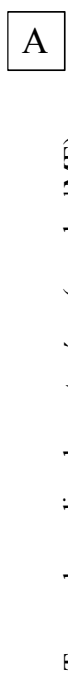

A

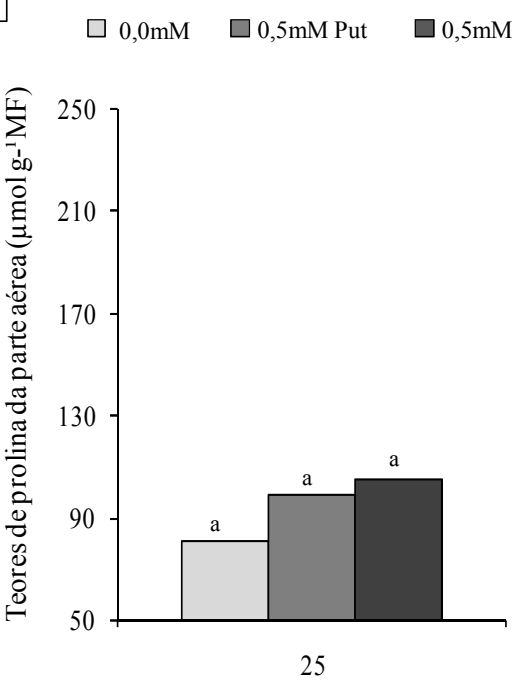

Temperatura ótima $\left({ }^{\circ} \mathrm{C}\right)$
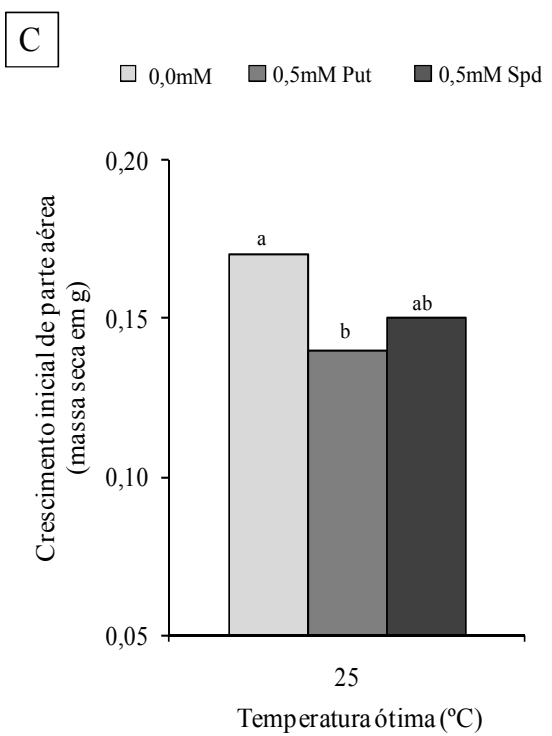

B

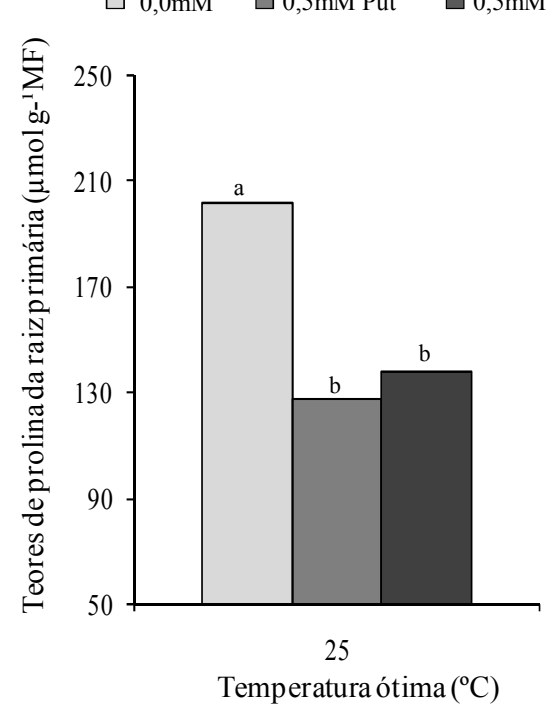

$\mathrm{D}$

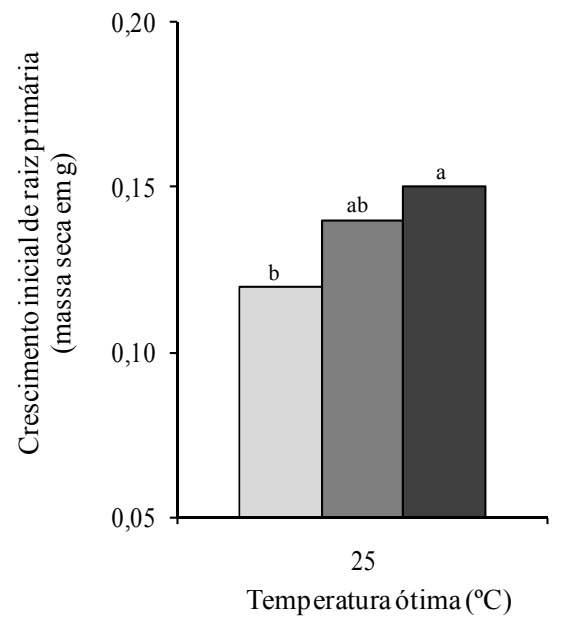

Fonte: Elaboração dos autores. 
Figura 11. Conteúdo de prolina e crescimento inicial de plântulas de guandu, cv. Caqui, em temperatura não estressante e poliaminas exógenas, no $10^{\circ}$ dia após a semeadura. Parte aérea (A e C) e raiz primária (B e D). * Médias seguidas da mesma letra, maiúscula (entre tempos de exposição ou temperatura) e minúscula (dentro de cada tempo de exposição ou temperatura), não diferem entre si pelo teste de Tukey $(\mathrm{P}>0,05)$.

A

$\square 0,0 \mathrm{mM}$

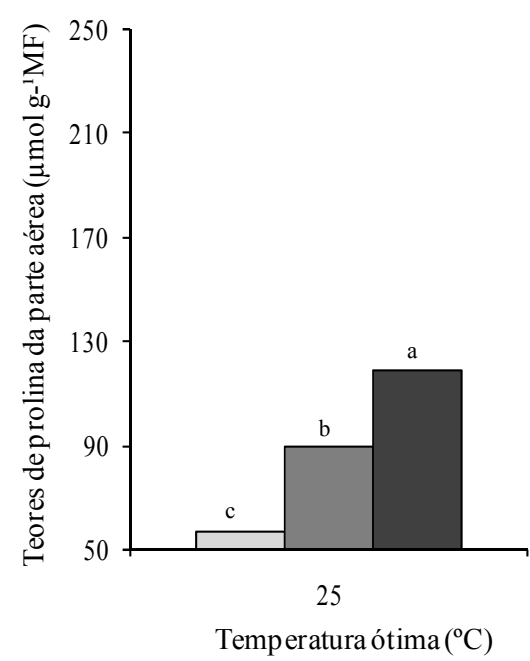

$\mathrm{C}$

B

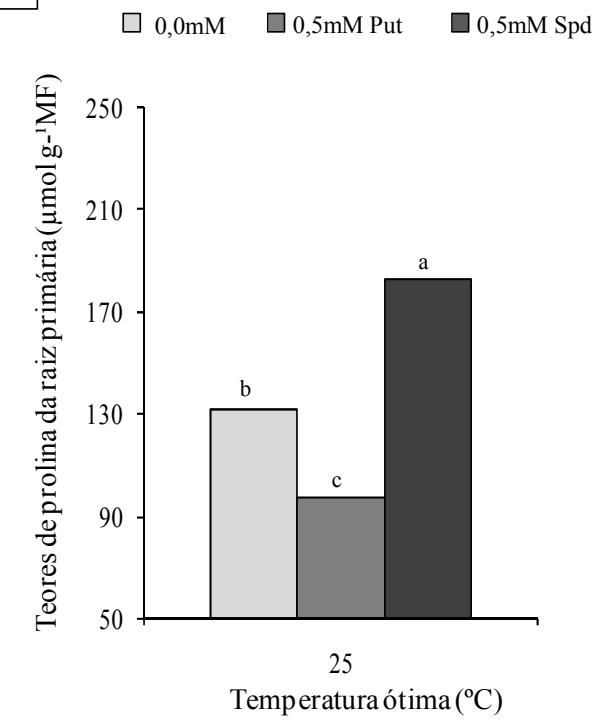

D

$0,5 \mathrm{mM}$ Spd

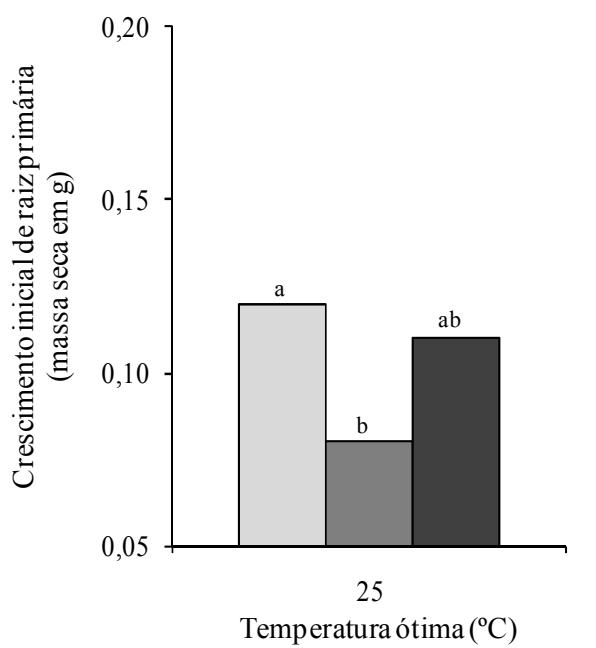

Fonte: Elaboração dos autores.

\section{Discussão}

A redução da germinação das sementes sob temperaturas baixas observada neste trabalho, evidencia a sensibilidade de espécies de clima tropical, como o guandu e a alfafa (WANG et al.,

2009) e o feijão (ZEID et al., 2004) ao resfriamento mais severo, Ranawake e Nakamura (2011) relatam que, temperaturas mais baixas reduzem a fluidez das membranas, podendo desencadear a seca fisiológica, que torna a água indisponível ao organismo, mesmo estando presente, prejudicando o processo 
germinativo que é uma das etapas mais sensíveis e importantes do desenvolvimento vegetal. Ainda, a maior porcentagem de germinação das sementes submetidas às baixas temperaturas por mais tempo, pode estar relacionada à capacidade de aclimatação do vegetal, uma vez que esta acontece a partir de uma exposição prévia à condição estressante, neste caso o período de 24 horas. Esta resposta fisiológica assemelha-se a observada em feijão (Phaseolus vulgaris L.) por Custódio et al. (2009), os quais verificaram que as sementes submetidas ao resfriamento prévio, não só germinaram mais, como apresentaram menor taxa de plantas anormais.

Semelhantes aos efeitos encontrados para o resfriamento, as temperaturas supraótimas desencadearam redução da germinação conforme aumento da temperatura, como verificado por Raveneau et al. (2011) em sementes de ervilha e feijão. Pode, neste caso, ter havido aumento da fluidez das membranas celulares e, consequentemente, o desarranjo celular. Também, pode ter havido desnaturação de proteínas e inativação de enzimas, haja vista que estas são compostos termo dependentes, desencadeando alterações em processos determinantes ao crescimento vegetal, como a respiração. A exposição das sementes às temperaturas altas pode acelerar a senescência, reduzir a viabilidade das sementes conduzindo a perda de rendimento, pois as plantas desviam recursos para lidar com o estresse por aquecimento, tornando os fotossintatos disponíveis, limitados ao desenvolvimento da planta (WAHID et al., 2007).

A aplicação das poliaminas Put e Spd mostrou efeito positivo nas sementes, principalmente na cultivar BRS Mandarim, sob temperaturas supraótimas. As poliaminas, de modo geral, podem ter atuado como osmoprotetores, uma vez que amenizaram os efeitos causados pelas temperaturas elevadas nas sementes. As temperaturas elevadas conduzem à deficiência hídrica celular, oriunda do aquecimento dos tecidos vegetais (CAVUSOGLU; KABAR, 2007; ASHRAF et al., 2008; GILL;
TUTEJA, 2010). Na cultivar Caqui, somente a Spd melhorou a germinação, mostrando a provável sensibilidade das rotas enzimáticas dessa cultivar às temperaturas supraótimas com tratamento de Put. A concentração da Put aplicada pode ter interferido na resposta germinativa, como verificado em sementes de pimenta que germinaram mais quando tratadas com soluções de baixas concentrações de Put (KHAN et al., 2012).

As poliaminas exógenas proporcionaram maior crescimento das plântulas, proporcionando incremento da massa seca das partes aéreas e raízes primárias, como verificado por Shen, Nada e Tachibana (2000) e Khan et al. (2012), que relacionam este incremento à divisão celular estimulada pelas poliaminas, devido a elas serem consideradas reguladores vegetais, agirem como protetores contra a peroxidação lipídica das membranas celulares através da inativação da NADPH oxidase e estabilizarem tais membranas, ligando-se a elas.

A redução dos teores de prolina deve-se, provavelmente, ao fato de as poliaminas e a prolina apresentarem os mesmos substratos para biossíntese, os aminoácidos glutamato e arginina. $\mathrm{O}$ aumento da concentração das poliaminas, pela adição destas substâncias às sementes somada às poliaminas endógenas, e diante das temperaturas impostas, fez com que os substratos glutamato e arginina fossem utilizados para a síntese de novo das poliaminas, deixando de biossintetizar a prolina (BRITIÁN et al., 2012). Esta redução pode, ainda, ser derivada da síntese de GABA pela planta, o qual apresenta os mesmos precursores da prolina e das poliaminas e também pelo fato das poliaminas terem sinalizado o aumento de outro osmoprotetor, seja enzimático e/ou soluto compatível, que não a prolina (ALCÁZAR et al., 2011; CVIKROVÁ et al., 2012). Nas plantas superiores, este aminoácido atua como osmoregulador ou sinalizador das respostas fisiológicas aos estresses mediante regulação do $\mathrm{pH}$ celular (ROBERTS, 2007; HUSSAIN et. al., 2011). 
Todavia, em alguns casos foi observada a resposta inversa, isto é, no tratamento com poliaminas houve aumento de prolina, semelhante aos resultados de Amri e Shahsavar (2010) com espermidinia exógena em citrus. Isto pode ter ocorrido como resultado da transdução mais eficaz do sinal de estresse osmótico devido à alta concentração de poliaminas no meio, promovendo acúmulo de prolina para proteger o organismo vegetal das injúrias causadas do déficit hídrico oriundo das temperaturas adversas (KUZNETSOV; SHEVYKOVA, 2007). Outro aspecto a considerar, é que o estresse por temperaturas supraótimas desencadeia o estresse oxidativo como resultado do desbalanço entre as reações fotoquímicas e bioquímicas, e assim, o metabolismo vegetal é estimulado a acumular prolina na tentativa de controlar a ação das espécies reativas ao oxigênio (EROS), responsáveis por grande parte da morte celular durante as condições de estresse (WAHID et al., 2007; SOLIMAN et al., 2012).

\section{Conclusões}

As poliaminas exógenas não atenuam os efeitos do resfriamento na germinação de sementes de ambas cultivares de guandu.

Os efeitos negativos do estresse térmico por aquecimento na germinação das sementes são atenuados pela Put e Spd exógenas.

Nas plântulas, as poliaminas exógenas atenuam os efeitos das temperaturas subótimas e supraótimas por induzir o acúmulo de prolina.

O aminoácido prolina pode ser considerado indicador bioquímico-fisiológico em plântulas de guandu sob temperaturas adversas.

\section{Agradecimentos}

Ao professor Dr. José Carlos Barbosa, pelo auxílio com a estatística do trabalho e ao CNPq pela concessão da bolsa de mestrado.

\section{Referências}

ABDUL JALEEL, C.; MANIVANNAN, P.; KISHOREKUMAR, A.; SANKAR, B.; GOPI, R.; SOMASUNDARAM, R.; PANEERSEKVAM R. Alterations in osmoregulations, antioxidant enzymes and indol alkaloid levels in Catharanthus roseus exposed to water deficit. Colloids and Surfaces B: Biointerfaces, Amsterdam, v. 59, n. 2, p. 150-157, 2007.

ALCÁZAR, R.; CUEVAS, J. C.; PLANAS, J.; ZARZA, X.; BORTOLOTTI, C.; CARRASCO, P.; SALINAS, J.; TIBURCIO, A. F.; ALTABELLA, T. Integration of polyamines in the cold acclimation response. Plant Science, Limerick, n. 180, p. 31-38, 2011.

AMRI, E.; SHAHSAVAR, A. R. Response of lime seedlings (Citrus aurantifolia L.) to exogenous spermidine treatments under drought stress. Australian Journal of Basic and Applied Sciences, Jordan, v. 4, n. 9 , p. 4483-4489, 2010.

ASHRAF, M.; AKRAM, N. A.; AL-QURAINY, F.; FOOLAD, M. R. Drought tolerance: roles of organic osmolytes, growth regulators and mineral nutrients. Advances in Agronomy, San Diego, v. 111, n.1, p. 249296, 2011.

ASHRAF, M.; ATHAR, H. R.; HARRIS, P. J. C.; KWON, T. R. Some prospective strategies for improving crop salt tolerance. Advances in Agronomy, San Diego, v. 97, n .1, p. 45-110, 2008.

BATES, L. S.; WALDREN, R. P.; TEARE, I. D. Rapid determination of free proline for water stress studies. Plant and Soil, The Hague, v. 39, n. 1, p. 205-207, 1973.

BRITIÁN, M.; ZARZA, X.; ALTABELLA, T.; TIBURCIO, A. F.; ALCÁZAR, R. Polyamines under abiotic stress: metabolic crossroads and hormonal crosstalks in plants. Metabolites, Basel, v. 2, n. 3, p. 516$528,2012$.

BRITO, L. K. F. L.; SILVEIRA, J. A. G.; LIMA, L. L. F.; TIMÓTEO, A. R. S.; CHAGAS, R. M.; MACEDO, C. E. C. Alterações no perfil de frações nitrogenadas em calos de cana-de-açúcar induzidas por deficit hídrico. Pesquisa Agropecuária Brasileira, Brasília, v. 43, n. 6, p. 683-690, 2008.

CAO, H. X.; SUN, C. X.; SHAO, H. B.; LEI, X. T. Effects of low temperature and drought in physiological and growth changes in oil palm seedlings. African Journal of Biotechnology, Amsterdam, v. 10, n. 14, p. 2630-2637, 2011.

CAVUSOGLU, K.; KABAR, K. Comparative effects of some plant growth regulators on the germination of 
barley and radish seeds under high temperature stress. EurAsian Journal of BioSciences, Turkey, v. 1, n. 1, p. 1-10, 2007.

CUSTÓDIO, C. C.; VIVAN, M. R.; NUNES, R. C. A.; AGOSTINI, E. A. T. Tolerância cruzada induzida por choque térmico na Germinação de semente de feijão. Revista Brasileira de Sementes, Brasília, v. 31, n. 1, p.131-143, 2009.

CVIKROVÁ, M.; GEMPERLOVÁ, L.; DOBRÁ, J.; MARTINCOVÁ, O.; PRÁSIL, I. T.; GUBIS, J.; VANKOVÁ, R. Effect of heat stress on polyamine metabolism in proline-over-producing tobacco plants. Plant Science, Limerick, v. 182, n. 1, p. 49-58, 2012.

GILL, S. S.; TUTEJA, N. Polyamines and abiotic stress tolerance in plants. Plant Signaling \& Behavior, Austin, v. 5, n. 1, p. 26-33, 2010.

HUSSAIN, S. S.; ALI, M.; AHMAD, M.; SIDDIQUE, K. H. M. Polyamines: Natural and engineered abiotic and biotic stress tolerance in plants. Biotechnology Advances, New York, v. 29, n. 3, p. 300-311, 2011.

KHAN, H. A.; ZIAF, K.; AMJAD, M.; IGBAL, Q. Exogenous application of polyamines improves germination and early seedling growth of hot pepper. Chilean Journal of Agricultural Research, Santiago de Chile, v. 72, n. 3, p. 429-433, 2012.

KUZNETSOV, V. V.; SHEVYAKOVA, N. I. Polyamines and stress tolerance of plants. Plant Stress, Kagawa, v. 1, n. 1, p. 50-71, 2007.

LOPES, H. M.; MENEZES, B. R. S.; SILVA, E. R.; SILVA, A. L. M. Avaliação da qualidade fisiológica de sementes de tomate (Lycopersicum esculentum L.) e de cenoura (Daucus carota L.) osmocondicionadas em olução aerada de PEG 6000. Revista Universidade Rural Série Ciências da Vida, Seropédica, v. 30, n. 2, p. 71-83, 2010 .

NENE, Y. L.; HALL, S. D.; SHEILA, U. K. The pigeonpea. Cambridge: CAB, 1990. 490 p.

RANAWAKE, A. L.; NAKAMURA, C. Cold tolerance of an inbred line population of rice (Oryza sativa L.) at different growth stages. Tropical Agricultural Research \& Extension, Sri Lanka, n. 14, v. 2, p. 25-33, 2011.

RAVENEAU, M. P.; COSTE, F.; MOREAUVALANCOGNE, P.; LEJEUNE-HÉNAUT, I.; DURR, C. Pea and bean germination and seedling responses to temperature and water potential. Seed Science Research, Wallingford, v. 21, n. 3, p. 205-213, 2011.
ROBERTS, M. R. Does GABA act as a signal in plants? Hints from molecular studies. Plant Signal Behavior, Austin, v. 2, n. 5, p. 408-409, 2007.

SAXENA, K. B. Genetic improvement of pigeon pea - a review. Tropical Plant Biology, New York, v. 1, n. 2, p. 159-178, 2008.

SHEN, W.; NADA, K.; TACHIBANA, S. Involvement of polyamines in the chilling tolerance of cucumber cultivars. Plant Physiology, Minneapolis, v. 124, n. 1, p. 431-439, 2000.

SOLIMAN, W. S.; FUJIMORI, M.; TASE, K.; SUGIYAMA, S. Heat tolerance and suppression of oxidative stress: comparative analysis of 25 cultivars of the C3 grass Lolium perenne. Environmental and Experimental Botany, Elmsford, v. 78, n. 1, p. 10-17, 2012.

SZABADOS, L.; KOVÁCS, H.; ZILBESTEIN, A.; BOUCHEREAU, A. Plants in extreme environments: importance of protective compounds in stress tolerance. Advances in Botanical Research, London, v. 57, n. 1, p. 106-133, 2011.

SZABADOS, L.; SAVOURÉ, A. Proline: a multifunctional amino acid. Trends in Plant Science, Netherlands, v. 15, n. 2, p. 89-97, 2010.

THAKUR, P.; KUMAR, S.; MALIK, J. A.; BERGER, J. D.; NAYYAR, H. Cold stress effects on reproductive development in grain crops: An overview. Environmental and Experimental Botany, Elmsford, v. 67, n. 3, p. 429443, 2010.

WAHID, A.; GELANI, S.; ASHRAF, M.; FOOLAD, M. R. Heat tolerance in plants: an overview. Environmental and Experimental Botany, Elmsford, v. 61, n. 3, p. 199223, 2007.

WANG, W. B.; KIM, Y. H.; LEE, H. S.; DENG, X. P.; KWAK, S. S. Differential antioxidation activities in two alfafa cultivars under chilling stress. Plant Biotechnology Reports, Germany, v. 3, n. 4, p. 301-307, 2009.

WIMALASEKERA, R.; TEBARTZ, F.; SCHERER, G. F. E. Polyamines, polyamine oxidases and nitric oxide in development, abiotic and biotic stresses. Plant Science, Limerick, v. 181, n .5, p. 593-603, 2011.

ZEID, I. M. Response of bean (Phaseolus vulgaris) to exogenous putrescine treatment under salinity stress. Pakistan Journal of Biological Sciences, Pakistan, v. 7, n. 2, p. 219-225, 2004. 